\title{
Evaluation and Management of Velopharyngeal Incompetence
}

\author{
K. Srinath ${ }^{1}$, Y. Suneel Kishore ${ }^{2}$, V. Sivarami Reddy ${ }^{3}$, B.R. N. Padmini ${ }^{4}$ \\ ${ }^{1}$ Assistant Professor, Department of Plastic Surgery, MNJ Cancer Institute, Hyderabad, ${ }^{2}$ Assistant Professor, Department \\ of General Surgery, Government Medical College and Hospital, Ongole, ${ }^{3}$ Retd Professor, Department of Plastic Surgery, \\ Osmania Medical College, Hyderabad, ${ }^{4}$ Assistant Professor, Department of General surgery, Siddhartha medical College, \\ Vijayawada, India
}

Corresponding author: Y. Suneel Kishore, s/o y. Subbarao, H.no 39-8-20-1a, Gopalnagaram First Lane, Ongole, Prakasam District,523001, Andhra Pradesh, India

DOI: http://dx.doi.org/10.21276/ijcmsr.2019.4.3.53

How to cite this article: K. Srinath, Y. Suneel Kishore, V. Sivarami Reddy, B.R. N. Padmini. Evaluation and management of velopharyngeal incompetence. International Journal of Contemporary Medicine Surgery and Radiology. 2019;4(3):C237-C240.

\section{A B S T R A C T}

Introduction: Palatoplasty for cleft lip and palate is associated with two major complications speech development disorders, including velopharyngeal insufficiency, and maxillary growth disturbance. Current study aimed to assess velopharyngeal incompetence and anatomical factors contributing to incomplete closure following cleft palate repair and to evaluated the patients after the surgical procedure and attempted to recommend an appropriate management strategy.

Materials and Methods: A prospective observational study was conducted from January 2011 to January-2013. A total of 28 patients with operated cleft palate having clinical features of velopharyngeal insufficiency were included in the study. Patients were evaluated by history, physical examination, Video fluoroscopy, Nasoendoscopy. Velopharyngeal gap size and closure pattern were taken into account based on the endoscopy report. Velopharyngeal gap size was rated on a four-point scale.

Results: Among our study participants, 9 (32\%) were aged between 11 to 15 years, and 16 (57\%) were males. Out of 28 cases with velopharyngeal incompetence, who were assessed endoscopically, the distribution of closure pattern was circular in $20(72 \%)$ cases. There were no patients found with sagittal closure pattern.

Conclusion: Our study concluded that Surgical correction of VPI improves speech and patients are advised speech therapy to improve the compensatory articulations.

Keywords: Velopharyngeal Incompetence, Cleft Palate Surgery, Hyderabad

\section{INTRODUCTION}

The soft palate (velum) is a fibromuscular shelf made up of five muscles attached as a sling to the posterior portion of the hard palate. It functions to elevate the nasopharynx, effectively closing the communication from the nasopharynx to the oropharynx. ${ }^{1}$

The velopharynx is a complex structure that is responsible for the separation of the oral and nasal cavities during speech production and swallowing. ${ }^{2}$ Velopharyngeal closure refers to the normal opposition of the soft palate, or velum, with the posterior and lateral pharyngeal walls. It is primarily a sphincteric mechanism consisting of a velar component and a pharyngeal component. Movement of the velar component is produced principally by the action of the levatorveli palatini muscle. The functional goals of cleft palate surgery are to facilitate normal speech and hearing without interfering with the facial growth of a child. ${ }^{3}$

Velopharyngeal dysfunction (VPD) refers to any situation in which an individual is unable to completely close the nasal airway during a speech. VPD can manifest as hypernasality, nasal emission, decreased vocal intensity, and/or facial grimacing. Moreover, patients who suffer from VPD will frequently develop maladaptive articulations to compensate for their speech difficulties.

VPI has been differentially interpreted as denoting insufficiency, incompetence, and inadequacy - terms that may be similar, but are not synonymous and potentially implicate the cause of the dysfunction rather than describe the clinical finding. VPD is seen in roughly 20 to $30 \%$ of individuals who have undergone cleft palate repair, and 5 to $10 \%$ of patients with a submucous cleft palate (SMCP).

Cleft palate represents the third most frequently occurring congenital deformity after clubfoot and cleft lip. If the cleft palate is left untreated, it may lead to velopharyngeal insufficiency (VPI) and speech distortion as the child grows. ${ }^{4}$ Some neuromuscular aetiologies can also result in VPD and are occasionally referred to as velopharyngeal incompetence. Childhood apraxia of speech is a motor speech disorder that hinders appropriate coordination of muscle movements for appropriate function. Hypernasality increases with connected speech and is associated with inconsistent articulation errors. Neurologic impairment, congenital abnormalities, or traumatic/iatrogenic injury are among some of the other 
myoneuronaletiologies that can render the velopharyngeal apparatus "incompetent," leading to VPD. ${ }^{5}$ VPI caused by cleft palate is amenable for surgical intervention.

The functional goals of cleft palate surgery are normal speech, hearing, and maxillofacial growth. It is generally thought that speech and hearing are improved by early cleft palate repair (before 24 months of age) and that delayed closure (after 4 years) is associated with less retardation of midfacial growth. The primary goal in the timing of cleft palate surgery, therefore, is to provide the adequate palatal function for the development of normal speech without interfering significantly with maxillofacial growth. ${ }^{6}$

The present study was conducted to assess velopharyngeal incompetence and anatomical factors contributing to incomplete closure following cleft palate repair. We have also evaluated the patients after the surgical procedure and attempted to recommend an appropriate management strategy.

\section{MATERIAL AND METHODS}

The current study was a prospective observational study done in was Department of Plastic Surgery, Osmania General Hospital, Hyderabad, which included operated cleft palate patients having clinical features of velopharyngeal insufficiency.

Study duration: The data collection for the study was

\begin{tabular}{|l|l|}
\hline Age (Years) & Number (\%) \\
\hline $5-10$ & $6(21 \%)$ \\
\hline $11-15$ & $9(32 \%)$ \\
\hline $16-20$ & $8(29 \%)$ \\
\hline $21-25$ & $5(18 \%)$ \\
\hline Sex distribution & $16(57 \%)$ \\
\hline Male & $12(43 \%)$ \\
\hline Female & Table-1: Age and gender distribution of VPI cases (N=28) \\
\hline
\end{tabular}

\begin{tabular}{|l|c|}
\hline Type of cleft & No of cases \\
\hline Unilateral Cleft lip and palate & $14(50 \%)$ \\
\hline Bilateral Cleft lip and palate & $8(29 \%)$ \\
\hline Isolated Cleft palate & $6(21 \%)$ \\
\hline Table-2: Type of cleft associated with velopharyngeal incom- \\
petence
\end{tabular}

conducted from January 2011 to January-2013.

Ethical approval: The study was approved by the Institutional Human Ethical Committee and informed written consent was obtained from all the participants.

Procedure: Patients were evaluated by history, physical examination, Video fluoroscopy, Nasoendoscopy. Nasoendoscopic examination was done in the department of ENT, Govt ENT Hospital, Koti. Velopharyngeal gap size and closure pattern were taken into account based on the endoscopy report.

Velopharyngeal gap size was rated on a four-point scale. Closure pattern was considered in 3 parts that included sagittal, coronal, and circular. We recorded the speech sample for 20 seconds each (lateral and Townes view); an average of the standard maximum measurements was obtained and velopharyngeal function was reported. The follow-up period ranged from eighteen months to three months. Patients were evaluated during the follow up period for improvement of symptoms and video fluoroscopy and nasoendoscopy and compared with the preop values.

\section{STATISTICAL ANALYSIS}

Data was presented as mean and standard deviation for quantitative variables, frequency and proportion of categorical variables. IBM SPSS version 21 was used for data analysis.

\section{RESULTS}

Among the study population, 6(21\%) participants were aged between 5 to 10 years, 9 (32\%) were aged between 11 to 15 years, 8 (29\%) were aged between 16 to 20 years, 5 (18\%) were aged between 21 to 25 years. 16 (57\%) were participants male

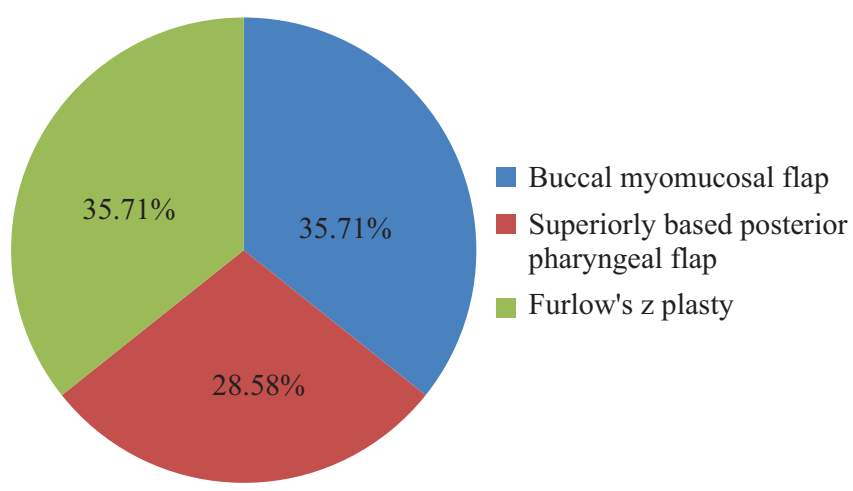

Figure-1: Types of Procedures done for Correction of VPI

\begin{tabular}{|l|c|l|}
\hline Parameter & Number (\%) & \multicolumn{1}{|l|}{ Choice of Procedure } \\
\hline Gap Size & $5(17.8 \%)$ & Furlow's Palatoplasty \\
\hline Small Gap(3-5mm) & $13(46.4 \%)$ & $\begin{array}{l}\text { Furlow's Palatoplasty } \\
\text { Buccal My mucosal Flaps }\end{array}$ \\
\hline Medium Gap(6-10mm) & $10(35.8 \%)$ & $\begin{array}{l}\text { Pharyngeal Flaps } \\
\text { Buccal My mucosal Flaps }\end{array}$ \\
\hline Large Gap(>10mm) & \multicolumn{1}{|c|}{} \\
\hline Closure Pattern & $20(71.42 \%)$ & $\begin{array}{l}\text { Pharyngeal Flaps } \\
\text { Buccal My mucosal flaps }\end{array}$ \\
\hline Circular & $8(28.58 \%)$ & $\begin{array}{l}\text { Furlow's Palatoplasty } \\
\text { Buccal My mucosal Flaps }\end{array}$ \\
\hline Coronal & \multicolumn{2}{|c|}{} \\
\hline
\end{tabular}


and remaining 12 (43\%) participants were female. (Table 1) Out of these 28 cases of VPI 14(50\%) were unilateral cleft lip and palate, $8(29 \%)$ were cases of bilateral Cleft lip and palate and remaining6(21\%) were isolated cleft palate. (Table 2)

Among all other procedures 10 (35.71\%), patients underwent Furlow's z plasty for correction of VPI, another 10 (35.71\%) underwent buccal mucosal flap, remaining 8 (28.58\%) underwent superiorly based posterior pharyngeal flap. (Figure 1)

In our study, out of 28 cases with velopharyngeal incompetence, who were assessed endoscopically, the distribution of closure pattern was circular in 20(72\%) cases and coronal 8 (28\%), whereas there was no patient having closure pattern of sagittal. (Table 3 )

\section{DISCUSSION}

The present study was undertaken to evaluate the velopharyngeal incompetence in patients who were already operated for cleft palate earlier and having symptoms of the nasal twang of voice and history of nasal regurgitation. The patients were evaluated by pre-operative nasoendoscopy and video fluoroscopy and pre-operative VPI gap size and closure pattern were taken into account in planning the appropriate procedure. The patients were followed for a period ranging from eighteen months to three months and evaluated in the postoperative period for the improvement of symptoms any complications of the surgery and post op VPI gap size and closure pattern.

A study was conducted to utilize three-dimensional magnetic resonance imaging (MRI) to correlate velopharyngeal closure patterns with velopharyngeal anatomical structural characteristics. Velar length and adenoid thickness varied based on closure patterns, with coronal closure pattern demonstrating significantly larger values compared to circular closure pattern. There were no statistically significant differences for effective velar length, pharyngeal depth, nasopharyngeal length, posterior pharyngeal wall thickness, and nasopharyngeal width based on the type of closure pattern. Closure patterns varied by gender, with females demonstrating more circular closure patterns compared to males who demonstrated more coronal closure patterns. Statistically significant differences were observed in velopharyngeal anatomical structural measures and gender during evaluations of closure patterns. These preliminary findings indicate the length of the velum and thickness of the adenoids may have the greatest impact on velopharyngeal closure patterns. ${ }^{7}$ In our study, out of 28 cases with velopharyngeal incompetence, who were assessed endoscopically, the distribution of closure pattern was circular in $20(72 \%)$ cases and coronal 8 (28\%), whereas there was no patient having closure pattern of sagittal. Another study showed that Selection of the surgical procedure depending on the type of preoperative VPC pattern for the treatment of post palatoplasty VPI is an appropriate method. In case of a circular closure pattern, sphincter pharyngoplasty is the operation of choice as it has a lower incidence of postoperative snoring than pharyngeal flap. ${ }^{8}$ In a study of 148 consecutive patients, the conclusion was preoperative velopharyngeal gap size, as determined with nasoendoscopy, was significantly associated with postoperative velopharyngeal insufficiency severity after Fur low palatoplasty. Small gap size was associated with a greater likelihood of resolution. ${ }^{9}$

In another study author concluded that closure patterns vary based on gender, with females demonstrating a circular closure pattern compared to males who demonstrate more of a coronal closure pattern Velopharyngeal measures and gender revealed statistically significant differences when investigating closure patterns. ${ }^{10}$

In our study, out of the 10 patients treated with Furlow's double opposing z plasty. No complications were noted in any of the patients. All patients had satisfactory improvement of the nasal twang of voice and symptoms of nasal regurgitation had subsided. Complete closure was attained in 7 patients with preop VPI gapless than $5 \mathrm{~mm}$, but the closure was incomplete in 3 cases were the pre-op VPI gap was more than $5 \mathrm{~mm}$ with residual VPI gap of $2 \mathrm{~mm}$.

A retrospective study undertaken to assess speech outcomes in patients undergoing Furlow palatoplasty concluded that patients had a complete resolution or substantial improvement of velopharyngeal insufficiency postoperatively, and there were few surgical complications. ${ }^{11}$ In a retrospective study it was seen that participants who had had Furlow repairs were superior on measures of hypernasality, articulation, and total speech scores; and fewer pharyngeal flaps were required by Furlow subjects. ${ }^{12}$

A survey identified normal patient speech as the criterion of success after correctional surgery for VPI. Assessment and management of VPI in Great Britain and Ireland is a highly varied practice. When a palatal procedure is indicated, surgical approaches are tailored to address each individual's pattern of velopharyngeal closure deficiency. The surgeons surveyed reported this as being most accurately demonstrated by direct nasoendoscopic visualisation and dynamic multiplanar video fluoroscopic studies. ${ }^{13}$

A research stated that although the lavatory muscle sling might be disturbed by the redo $\mathrm{DOZ}$ procedure, the surgery was effective in correcting the residual VPI with low morbidity. ${ }^{14}$

In a study, Significant improvement of APA and nasalance score for oral and nasal sentences was achieved. Flexible nasopharyngoscopy showed complete velopharyngeal closure in 19 patients (82\%) postoperatively. Which stated Furlow palatoplasty is considered a useful treatment option for VPI in patients with previously repaired cleft palate, it improves the speech and velopharyngeal closure. ${ }^{15}$

In another research conclusion obtained was Doubleopposing Z-palatoplasty is a surgical technique that could be used successfully to correct velopharyngeal incompetence in selected secondary palatoplasty patients. This technique permits correction of velopharyngeal incompetence and restoration of the velopharyngeal mechanism irrespective of prior intravelarveloplasty and without accompanying loss in the nasal airway. Preoperative assessment can better identify those patients who are less likely to achieve velopharyngeal competence following double-opposing Z-palatoplasty alone. ${ }^{16}$

In our study out of the 8 patients treated with Superiorly based 
posterior pharyngeal flap, all patients have complained throat pain and difficulty in swallowing the immediate post-operative period, which was relieved with continued oral intake. In $n$ research results showed that superiorly based pharyngeal flap is highly successful in correcting VPI after Le Fort I maxillary advancement in patients with repaired CL/P. ${ }^{17}$ On late follow up, all patients had satisfactory improvement of the nasal twang of voice and the symptoms of nasal regurgitation had subsided. Among them 4 patients complained of snoring and halitosis. A retrospective chart review was conducted for 84 consecutive nonsyndromicpostpalatoplasty patients undergoing velopharyngeal insufficiency pharyngeal flap group showed postoperative snoring, and one (2.6 per cent) of them presented with obstructive sleep apnea. ${ }^{18}$ Snoring was because of narrowing of the effective velopharyngeal orifice and halitosis because of pooled up oral secretion over the flap. None of the patients had symptoms of obstructive sleep apnoea. In one study the significant number of middleaged adults with repaired cleft palate had OSA and related symptoms, regardless of the presence of a pharyngeal flap. Results suggest that VPI treatment with a flap may not cause sleep-disordered breathing in the cleft population. Besides advancing age, congenital upper airway abnormalities may be involved. Flap was viable in all the patients. 6 patients had VPI gap reduced from large preoperative gap to almost nil lateral port gaps and 2 patients had small lateral port gaps while assessing the velopharyngeal closure post operatively. Conclusion

In our research we concluded that Nasoendoscopy and video fluoroscopy could give an excellent assessment of velopharyngeal closure. Surgical correction of VPI corrects the symptoms of nasal regurgitation, reduces the respiratory problems and improves oral hygiene. Surgical correction of VPI improves speech and patients are advised speech therapy to improve the compensatory articulations.

\section{REFERENCES}

1. Matsui Y, Kurita K, Imaoka K, Hanai H, Mizuno S, Katayama Y, et al. Two-stage cleft palate closure by our treatment algorithm in complete unilateral cleft lip and palate: results of velopharyngeal function. J Oral Maxillofac Surg Med Pathol. 2019;31(2):65-70.

2. Raol N, Hartnick CJ. Anatomy and physiology of velopharyngeal closure and insufficiency. Adv Otorhinolaryngol. 2015;76(3):1-6.

3. Johns DF, Rohrich RJ, Awada M. Velopharyngeal incompetence: a guide for clinical evaluation. Plast Reconstr Surg. 2003;112(7):1890-8.

4. Kosowski TR, Weathers WM, Wolfswinkel EM, Ridgway EB. Cleft palate: Thieme Medical Publishers; 2012. 164-9 p.

5. Woo AS. Velopharyngeal dysfunction. Semin Plast Surg. 2012;26(4):170-7.

6. Rohrich RJ, Love EJ, Byrd HS, Johns DF. Optimal timing of cleft palate closure. Plast Reconstr Surg. 2000;106(2):413-21.

7. Jordan HN, Schenck GC, Ellis C, Rangarathnam B, Fang X, Perry JL. Examining Velopharyngeal Closure Patterns Based on Anatomic Variables. J Craniofac Surg. 2017;28(1):270-4.
8. Abdel-Aziz M, El-Hoshy H, Ghandour H. Treatment of velopharyngeal insufficiency after cleft palate repair depending on the velopharyngeal closure pattern. J Craniofac Surg. 2011;22(3):813-7.

9. Perkins JA, Lewis CW, Gruss JS, Eblen LE, Sie KC. Furlow palatoplasty for management of velopharyngeal insufficiency: a prospective study of 148 consecutive patients. Plast Reconstr Surg. 2005;116(1):72-80.

10. Jordan HN. Predicting Velopharyngeal Closure Patterns Based on Anatomic Variables: Master's Thesis. East Carolina University; 2016.

11. Sie KC, Tampakopoulou DA, Sorom J, Gruss JS, Eblen LE. Results with Furlow palatoplasty in management of velopharyngeal insufficiency. Plast Reconstr Surg. 2001;108(1):17-25.

12. McWilliams BJ, Randall P, LaRossa D, Cohen S, Yu J, Cohen M, et al. Speech characteristics associated with the Furlow palatoplasty as compared with other surgical techniques. Plast Reconstr Surg. 1996;98(4):610-9.

13. Hodgins N, Hoo C, McGee P, Hill C. A survey of assessment and management of velopharyngeal incompetence (VPI) in the UK and Ireland. J Plast Reconstr Aesthet Surg. 2015;68(4):485-91.

14. Hsu PJ, Wang SH, Yun C, Lo LJ. Redo doubleopposing Z-plasty is effective for correction of marginal velopharyngeal insufficiency. J Plastic Reconstr Aesthet Surg. 2015;68(9):1215-20.

15. Abdel-Aziz M, Nassar A, Rashed M, Naguib N, E1Tahan AR. Furlow palatoplasty for previously repaired cleft palate with velopharyngeal insufficiency. Int J Pediatr Otorhinolaryngol. 2015;79(10):1748-51.

16. Chim H, Eshraghi Y, Iamphongsai S, Gosain AK. Double-Opposing Z-Palatoplasty for Secondary Surgical Management of Velopharyngeal Incompetence in the Absence of a Primary Furlow Palatoplasty. Cleft Palate Craniofac J. 2015;52(5):517-24.

17. Dentino KM, Marrinan EM, Brustowicz K, Mulliken JB, Padwa BL. Pharyngeal flap is effective treatment for post maxillary advancement velopharyngeal insufficiency in patients with repaired cleft lip and palate. J Oral Maxillofac Surg. 2016;74(6):1207-14.

18. Yamaguchi K, Lonic D, Lee $\mathrm{CH}$, Wang SH, Yun C, Lo LJ. A Treatment Protocol for Velopharyngeal Insufficiency and the Outcome. Plast Reconstr Surg. 2016;138(2):E290-9.

\section{Source of Support: Nil; Conflict of Interest: None}

Submitted: 13-07-2019; Accepted: 15-08-2019; Published online: 21-09-2019 